\title{
Decision Support Model to Select Cushioning Material for Dynamics Hazards During Transportation
}

\author{
Á. Mojzes, P. Böröcz \\ Széchenyi István University, Department of Logistics and Forwarding \\ Egyetem tér 1., 9026 Győr, Hungary \\ Phone: +36 96503400 \\ e-mail: mojzesa@sze.hu
}

Abstract: Designing a product-packaging system is a complex challenge for engineers. Building a suitable and sustainable system the packaging engineers have to take into consideration many aspects, demands and requirements. To protect the product by packaging-system from physical events during transportation, handling and warehousing the cushioning has got a significant role, because this means the primary protection. This paper aims to give a model help to decide the applicability of different cushioning materials based on their protective, sustainable and economical attributions. This model ranks the different types of packaging materials choosing the final optimal solution. Our study also introduces a determinant, which is in connection with the mechanical characteristic (cushion curve) of the material on different environmental factors.

Keywords: packaging, cushioning, decision support model, product-package system,

\section{Introduction}

The aim of our paper is to present a model, which can be a support mechanism to the packaging engineers. During a packaging designing process, a lot of parameter and requirements have to be taking into consideration, like product protection or logistic environmental factors. It's well known that the primary protection of product can be ensured by any kind of known or innovative cushioning solution. By the described method in this paper, the decision can be performed in the early phase of designing process, between different cushion materials using primary. Comparing the possible versions by different aspects, engineers can decide which should be the best or optimal material. This paper introduces a parameter to modify and enlarge the equitation used in practice during testing and comparing cushion materials. This parameter is in connection with mechanical characteristic of material on different environmental parameters, so the ranking and comparison going to be more realistic for those cases where the material specially sensitive for relative humidity changes or 
temperature changes, and moisture can be appeared in very characteristics ways (like transcontinental transports). The model also can compare the continuously appearing new, innovative and environmentally friendly materials.

In this paper a solution is given, which can support the development processes of a product-packaging system. Groups were defined giving one of the most significant influences during a designing process. Also a basic function is performed, which can be a right solution, if the primary protection of product- cushioning systems should be compared and ranked. By this model all the parameters of influence group can take into account, except the behaviour of the mechanical characteristic on different environmental conditions. The basic model can be enough, when the materials nonsensitive for humidity or the cushioning characteristic is not a major issue.

\section{Model set-up and the its components}

When a product's designing processes is investigated, many of methods can be configured by former knowledge to make easier, more effective, make cheaper the product itself [1]. These designing processes mainly investigate the product design. Just some of the processes mention and work with the logistic and packaging aspects. [2] [3] Beside that, these models are become more and more complex; none of them deal with the packaging system as a complex system to protect product. These models are not able to give a help hand when the engineer have to choose the right, costeffective, optimal and mechanical suitable packaging protection system, like cushioning. Nowadays, this decision is getting more and more important, as the environmental regulations, waste requirements get higher accent, and the material science develops new materials, which are possible applicable for the packaging industry.

The described method in this paper helps and supports the decision policy among the possible suitable move-damping systems. By this, the possible cushion materials can be re-parameterized or modified if the consumer or the logistic environment requires subsequently this. To build up the model, at first, categories (parameter groups) have to be grouped which influence the product package system. Fig. 1 shows these groups. 


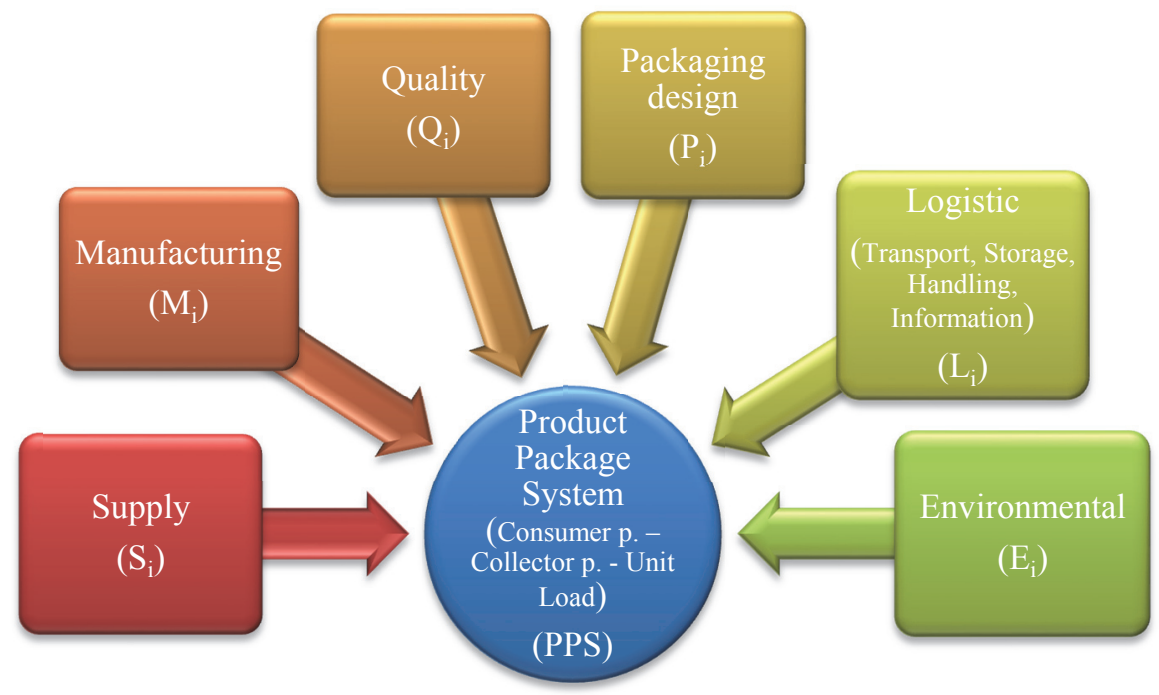

Figure 1. The Product - Package System

In the system, the groups mean the followings:

- PPS: (Product Package System): The complex system, which includes each package components and product protect devices. The result and sum of sub categories (described below) have to be the maximum, as the result of development.

- $\mathrm{S}_{\mathrm{i}}$ : (Supply): Category includes those information and parameters, which are important during the supply and purchasing process of PPS components. In case of this sub-category, the minimum (for example costs in EUR $/ \mathrm{m}^{3}$, etc.) of amounts is the most important ( $\left.\mathrm{S}_{\mathrm{i}} \rightarrow \mathrm{min}\right)$.

- $\mathrm{Q}_{\mathrm{i}}$ : (Quality): The quality parameters mean the most important factors in this sub-category. The maximizing of the criteria's $\left(\mathrm{Q}_{\mathrm{i}} \rightarrow \max \right)$ is the most important, like the percentage of fault free income packaging devices $(\% /$ $1000 \mathrm{pcs})$, etc.

- $\mathrm{M}_{\mathrm{i}}$ : (Manufacturing): Sum of parameters can be connected with the producibleness. In this category the minimization of the values $\left(\mathrm{M}_{\mathrm{i}} \rightarrow \min \right)$ is the aim, like manufacturing time ( $\mathrm{pcs} / \mathrm{min})$, switch over time ( $\mathrm{min} / \mathrm{pcs})$, etc.

- $\quad P_{i}$ : (Packaging): It contains the entire packaging system, built up around the product. Maximizing the contains $\left(\mathrm{P}_{\mathrm{i}} \rightarrow \max \right)$ of this sub category is the goal, like resistance of package devices, passing the functional requirements, percentage of intact products, etc.

- $\quad \mathrm{L}_{\mathrm{i}}$ : (Logistics): Those parameters are in this sub category, which are able to affect the effectiveness of transportation, handling and storage, like stackability ( $\mathrm{kg} /$ package), possibility of mechanical handling, etc. To maximize the parameters is the goal $\left(\mathrm{L}_{\mathrm{i}} \rightarrow \max \right)$. 
- $\mathrm{E}_{\mathrm{i}}$ : (Environment): This sub-category contains the parameters, which are important when the whole package is at the End-of-Life and becoming waste. To minimize the factors $\left(\mathrm{E}_{\mathrm{i}} \rightarrow \mathrm{min}\right)$, like package waste per product $(\mathrm{kg} / \mathrm{pc})$ or the degree of non-recyclable materials in the system, are the goals.

The contents of each sub-category can include many factors, so in the followings they are not detailed as a complete list. They are important when the model going to be improved in an exact task. The function (1) of the PPS is going to be the following, based on the Fig. 1:

$$
P P S_{i}=f\left(S_{i}, Q_{i}, E_{i}, L_{i}, M_{i}, P_{i}\right)
$$

Building up a product package system can be modified by each sub categories. The weight of the sub categories can be changed in each designing task, so a weighting coefficient has to be adopted.

For each of sub-categories the following coefficients (2) can be applied:

$$
a_{S}=\frac{S_{\min }}{S_{i}} ; a_{Q}=\frac{Q_{i}}{Q_{\max }} ; a_{M}=\frac{M_{\min }}{M_{i}} ; a_{P}=\frac{P_{i}}{P_{\max }} ; a_{L}=\frac{L_{i}}{L_{\max }} ; a_{E}=\frac{E_{\min }}{E_{i}} ;
$$

Based on the above written, the function (3) can be expressed for the value analysis:

$$
P P S_{i}=\left(a_{S} S_{i}+a_{Q} Q_{i}+a_{M} M_{i}++a_{L} L_{i}+a_{E} E_{i}\right) \cdot a_{P} P_{i}
$$

Where:

$\mathrm{S}_{\mathrm{i}}$ : the Supply, etc. sub category markings

as: the weight coefficient concerning to the sub-category, like Supply $\left(\mathrm{S}_{\mathrm{i}}\right)$, etc.

As from the function can be seen, the $a_{p} P_{i}$ block is factored out, because the protection of product is the major and primary task of a product package system. The parameters, which are applied to the weighting coefficients, can be modified or extended in order to fine the analysis. It is important that the coefficients have to be defined individually in each design development task. To verify the model test calculations was performed. The bases of calculations were the values of three types of different cushioning materials (Fig. 2).

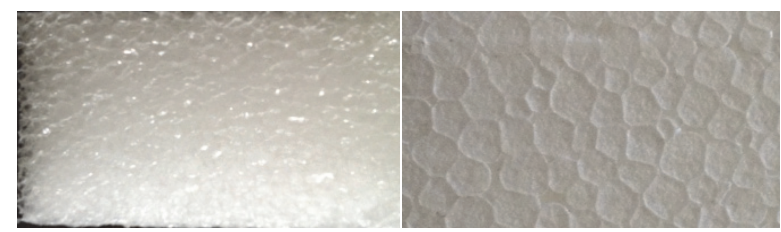

Sample 1. Polyethylene
Sample 2. Expanded Polystyrene

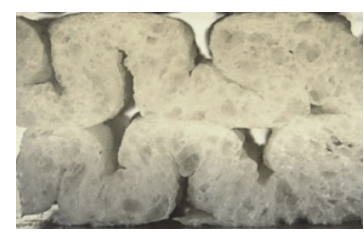

Sample 3. Thermo-Plastic Strach

Figure 2. Tested and compared cushions 
Two of them are common plastics foams (Polyethylene: PE and Expanded Polystyrene: EPS), and the third one is a new innovative and environmentally friendly material (Thermo-Plastic Starch: TPS). Comparing these different material versions the weighting values $\left(a_{i}\right)$ are same for each cushion, and the sub-category values are pre-defined and based on previous investigations and researches. With the calculation the types can be ranked and compared. Based on the results, it can be decided whether the new environmentally friendly material capable to be a final cushioning material or not. The comparison of the materials can be seen in Table 1 .

Table 1. Calculating and comparison the materials by categories

\begin{tabular}{|c|c|c|c|c|c|c|c|c|c|c|c|c|c|c|}
\hline & $\mathbf{S}_{\mathbf{i}}$ & as & $\mathbf{Q}_{\mathbf{i}}$ & $\mathbf{a}_{\mathbf{Q}}$ & $\mathbf{E}_{\mathbf{i}}$ & $a_{E}$ & $\mathbf{L}_{\mathbf{i}}$ & $\mathbf{a}_{\mathbf{L}}$ & $\mathbf{M}_{\mathbf{i}}$ & $\mathbf{a}_{\mathbf{M}}$ & $\mathbf{P}_{\mathbf{i}}$ & ap & $\begin{array}{l}\text { Cum. } \\
\text { Value }\end{array}$ & $\begin{array}{c}\Delta \\
\text { values } \\
(\%)\end{array}$ \\
\hline$P E$ & 4 & 35 & 8 & 20 & 5 & 30 & 9 & 30 & 5 & 25 & 10 & 60 & 507000 & $-9,1$ \\
\hline$\overline{E P S}$ & 2 & 35 & 7 & 20 & 7 & 30 & 10 & 30 & 7 & 25 & 10 & 60 & 537000 & $-3,8$ \\
\hline$T P S$ & 9 & 35 & 8 & 20 & 1 & 30 & 10 & 30 & 5 & 25 & 10 & 60 & 558000 & 0,0 \\
\hline & \multicolumn{2}{|c|}{$\mathrm{S}_{\mathrm{i} \rightarrow \min }$} & \multicolumn{2}{|c|}{$\mathrm{Q}_{\mathrm{i}} \rightarrow \max$} & \multicolumn{2}{|c|}{$\mathrm{E}_{\mathrm{i}} \rightarrow \min$} & \multicolumn{2}{|c|}{$\mathrm{L}_{\mathrm{i}} \rightarrow \max$} & \multicolumn{2}{|c|}{$\mathrm{M}_{\mathrm{i}} \rightarrow \min$} & \multicolumn{2}{|c|}{$\mathrm{P}_{\mathrm{i} \rightarrow \mathrm{max}}$} & & \\
\hline
\end{tabular}

The last column of the Table 1 is able to show the rank and the differences between the investigated materials. Actually, between the results, there are not so huge differences.

\section{Discussion of the modified model}

When a new material appears, many suitability tests, verification processes and investigations are required in order to be applied the given material in practice. It means a long time, huge amount of measurements, and of course it is a very expensive process. To make a decision about a new material, whether it is suitable or not, information are required from two aspects. The first aspect is the information and parameters written in the previous chapter, by a basic comparison. The second one is a knowledge about the given supply chain, where the possible material going to be applied as a product protection system.

Many papers investigated those influential logistical and environmentally parameters, which can have major influence on both product and packaging [4][5]. From two groups of logistic stresses, which are the mechanical and environmental affects, I had to choose the affects, can make the highest risk for the packaged product. Investigating these, the shock/drop and the temperature/humidity stayed as major effects.

There are papers, which investigated the cushion characteristics of different materials [6][7]. Several testing methods show relevant information, but one of the most important is the "cushion curve" test method [8]. A classical cushion curve can be seen on Fig. 4, when the material quality is tested in the function of thickness, drop height and static stress [9] [10]. If the engineers want to know the all-possible variation, it means a lot of tests and it requires a very long time. To solve this and to 
shorten the duration, the so-called Stress - Energy method can be a suitable solution [11] [12].

The dynamic stress can be defined in $G \cdot s$ ( $G$ times static loading), and the dynamic energy can be defined as $s \cdot h / t$ (static loading times drop height divided by cushion thickness). Both of them have units of Pascal [kPa].

This method says that for any calculated energy, $G$ can be predicted. Predicted $G$ levels have to be compared (from $G \cdot s$ ) to actual $G$ levels from the cushion curve in different combinations of $s, h$ and $t$. So, $G$ levels can be predicted very accurately.

$1^{\text {st }}$ step: The maximum and minimum limits on the energy absorbed have to be set. As Energy $=s \cdot h / t$, the minimum energy corresponds to the smallest $s$, the smallest $h$, and the largest $t$ that data to be wanted for. The maximum energy corresponds to the largest $s$, the largest $h$, and the smallest $t$ that data to be wanted for.

$2^{\text {nd }}$ step: Divide the energy range in step first into about 5-10 approximately evenly spaced points. If the range 5 to $100 \mathrm{kPa}$ is used, then test for energies in steps of about $20 \mathrm{kPa}$. So, 9 different energies could be chosen for equal to $20,40,60 \ldots$ and 100 kPa.

$3^{\text {rd }}$ step: For each of the energy step have to be chosen in the second step, select five-six different combinations of $(s),(h)$ and $(t)$ values that give this energy. Next, minimum 6 drops have to be performed with cushion tester (or drop tester). For the first drop, the cushion tester has to be set up for an equivalent free fall drop height of 400 millimeters, and a cushion sample can be selected with an actual thickness of 10 $\mathrm{mm}$. Enough weight has to be added to the platen in order to achieve a static stress of $1 \mathrm{kPa}$, and drop on the platen. The shock pulse can be captured the peak acceleration $(G)$ by recording machine (in this way we apply HBM-Spider 8 ). These have to be completed for the six drops corresponding to an energy of $20 \mathrm{kPa}$. Now we can summarize the experimental data in a table.

$4^{\text {th }}$ Step: Repeat step third for each of the energies (doing on the six levels of the total range) in the range chosen in second step and construct the stress vs. energy relationship shown below. The stress values listed are the means for the 5 replicates tested for each energy class.

$5^{\text {th }}$ step (optional: Fit an equation to the stress $(G)$ vs. energy data. The relationship between stress and energy can usually be described to a high degree of correlation by the exponential relationship:

$$
\text { stress }=a \cdot e^{b(e n e r g y)}
$$

where $(a, b)=$ constants specific to foam type and density and ( $e=2,71$ constant $)$

This regression can be used to best fit this equation to the data. The next step is to plot dynamic stress versus dynamic energy, and apply a simple exponential curve fit to the data points. 
Fig. 3 shows the applied instrumentations during the tests, which were are the following:

- COMETECH QC-113B1 drop tester (1)

- $\quad$ PCB piezoelectric tri-axial accelerometer (range: 0 - 300g) (2)

- Hottinger-Baldwin Messtechnik SPIDER 8 Analyser and Software Package (3)

- Loads (4)

- Cushioning sample material (5)

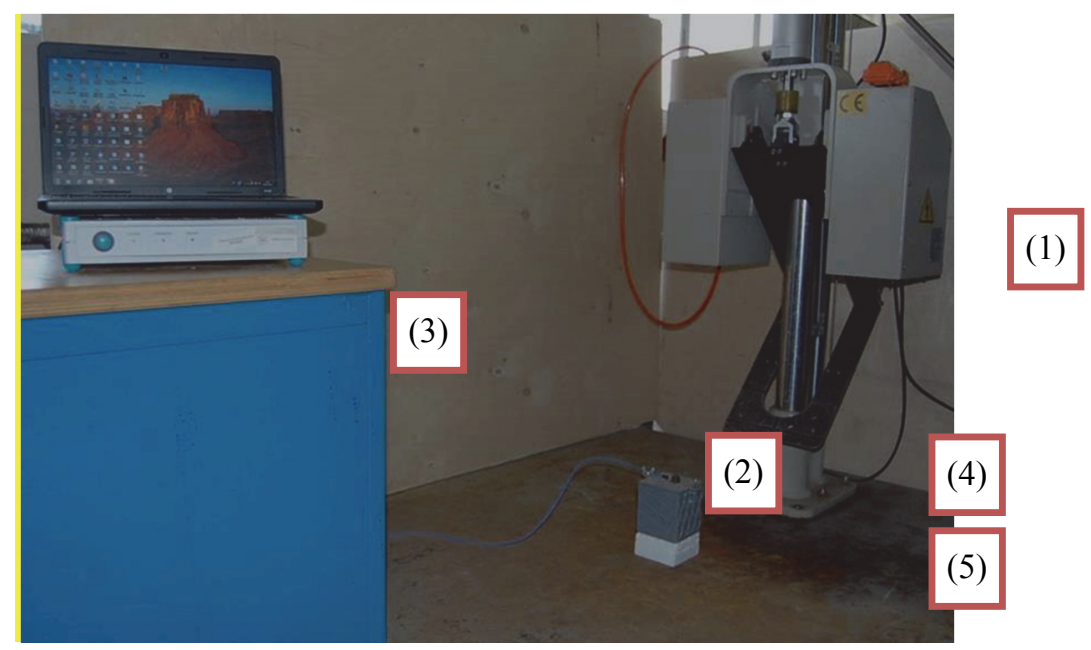

Figure 3. Measurement system for step 3 by drop test

By this 5 steps method, the points of the curve can be estimated considering the different variables. This estimation method can be seen in the Fig. 4 and 5. 


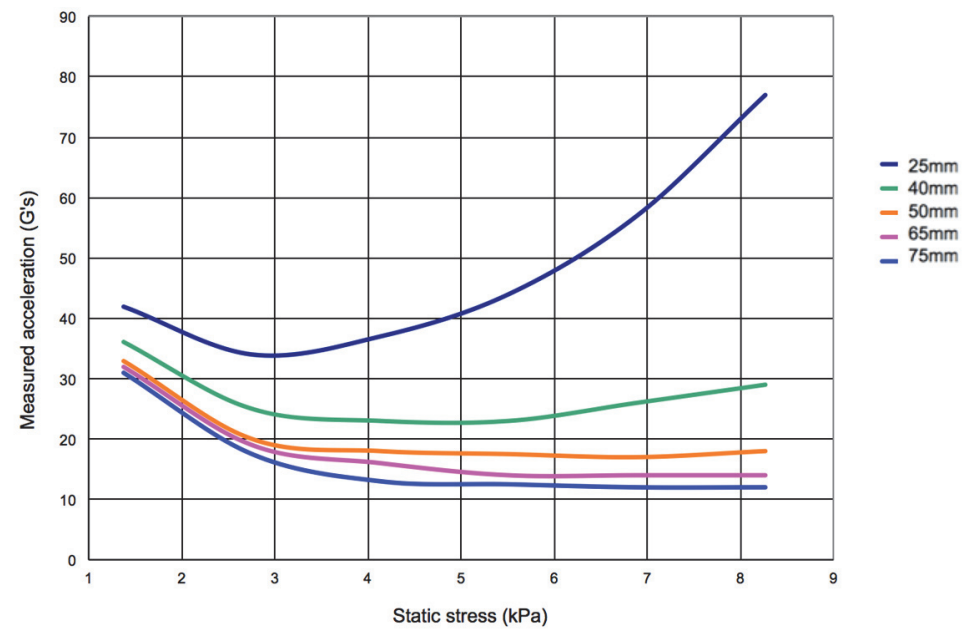

Figure 4. The cushion curves of TPS material (with different thickness')

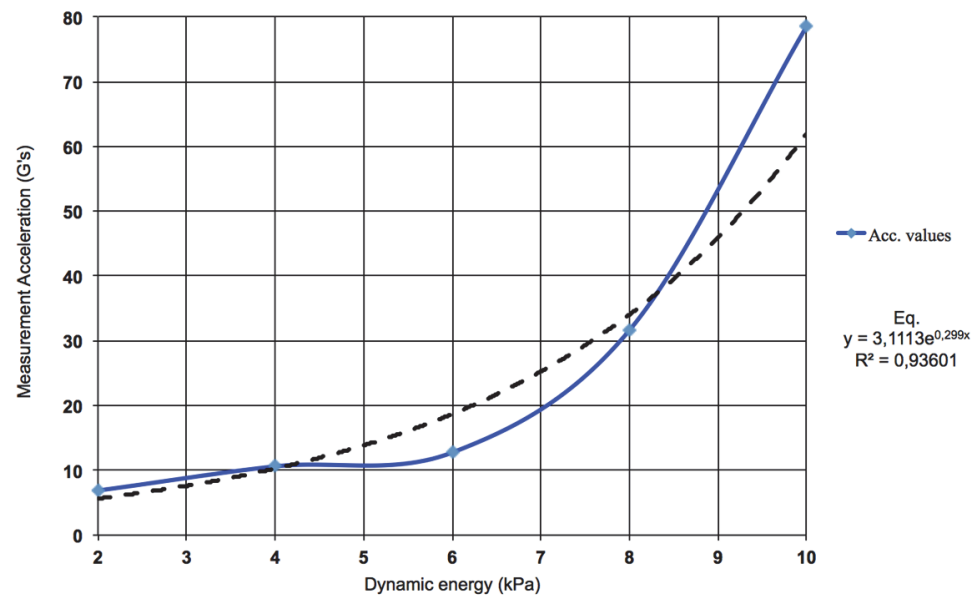

Figure 5. The Stress energy model of TPS foam on $23^{\circ} \mathrm{C}$ and $50 \% \mathrm{RH}$

It can be seen at first sight that an exponential function fits best to the measured values, and this is proved by both industrial and research projects. In this calculation the $\mathrm{R}^{2}$ also had showed that function assimilating to the measurements.

Nowadays, the continuous development and the environmental regulations more and more prefer to use natural materials, like corrugated fiberboard, honeycomb or innovative biodegradable materials as TPS foam is. The widely known problem with these materials is the sensitivity for changes of relative changes means some kind of mechanical property decrease.

To be able to apply these materials as a real packaging material on transportations with different circumstances where the humidity and temperature values changes so 
fast, the equation (3) has to be modified. The modification is necessary to be able to show the changes on those development projects, where a sensitive material has to be compared with others. It can be seen from the basic equation (3) that the final value affected majorly by the values of Packaging category $\left(\mathrm{P}_{\mathrm{i}}\right)$. So, if the mechanical behaviours of material on different environmental versions want to be taken into consideration, the new modifying factor has to be grouped into this category. This factor will be the modification factor $\alpha$. The $\alpha=\mathrm{f}\left(\mathrm{R}^{2}\right)$, where $\mathrm{R}^{2}$ is the determinant, and the Stress - Energy method will calculate the given function. A modification factor should be found, which is able to modify the full model and be able to show the suitability and applicability too. The function of modification factor (eq. 4) is going to be as follows:

$$
\alpha=R^{2}-\frac{1}{\left(R^{2}\right)^{m}}
$$

, where $0<\mathrm{R}^{2} \leq 1$ and $\mathrm{R}^{2} \rightarrow 0$, so the $\alpha \rightarrow-\propto$. The connection can be seen on Fig. 5.

The power of $m(1 \leq m)$ counted with $m=1$. Other tasks, the $m$ can be varied to any other value in connection with the given sensitiveness of product, or any other special characteristic. This can be seen on Fig. 6 .

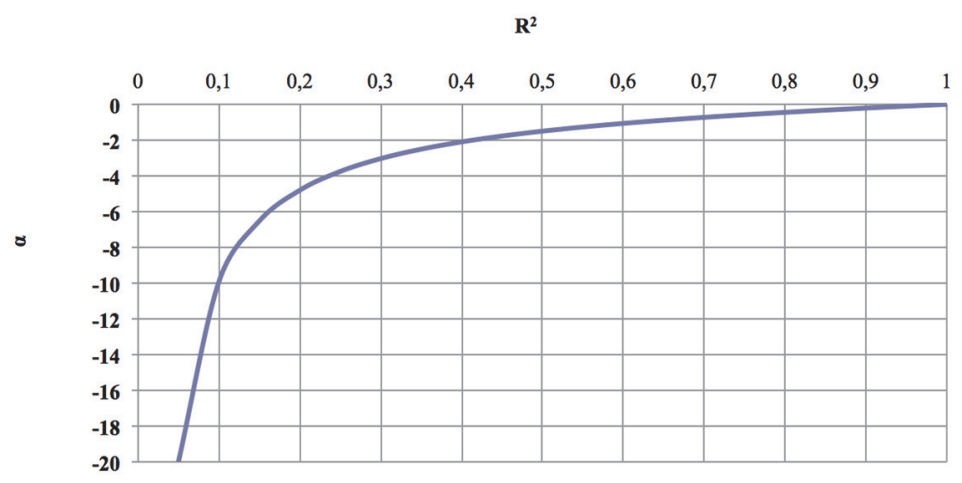

Figure 6. Connection of $R^{2}$ when $m=1$

According to the written above, the $\alpha$ is going to be implemented as a power of Packaging category. So, the basic equation extended with $\alpha$, going to be expressed as follow (5):

$$
P P S_{i}=\left(a_{S} S_{i}+a_{Q} Q_{i}+a_{M} M_{i}+a_{L} L_{i}+a_{E} E_{i}\right) \cdot a_{P} \cdot P_{i}^{\alpha}
$$

In the practice, it means the followings. Most of cushion curve and Stress-energy tests are performed on standard climate conditions $\left(23^{\circ} \mathrm{C} / 50 \% \mathrm{RH}\right)$. To be able to implement and investigate the humidity sensitiveness on materials, a $6^{\text {th }}$ step has to be add to the Stress - Energy method. This step is the investigation on variable 
environmental parameters, like different temperature and humidity values. Theoretically, it means small change in $\mathrm{R}^{2}$ value in case of common plastics foams, but for the natural and sensible materials can result significant decrease in $\mathrm{R}^{2}$ value.

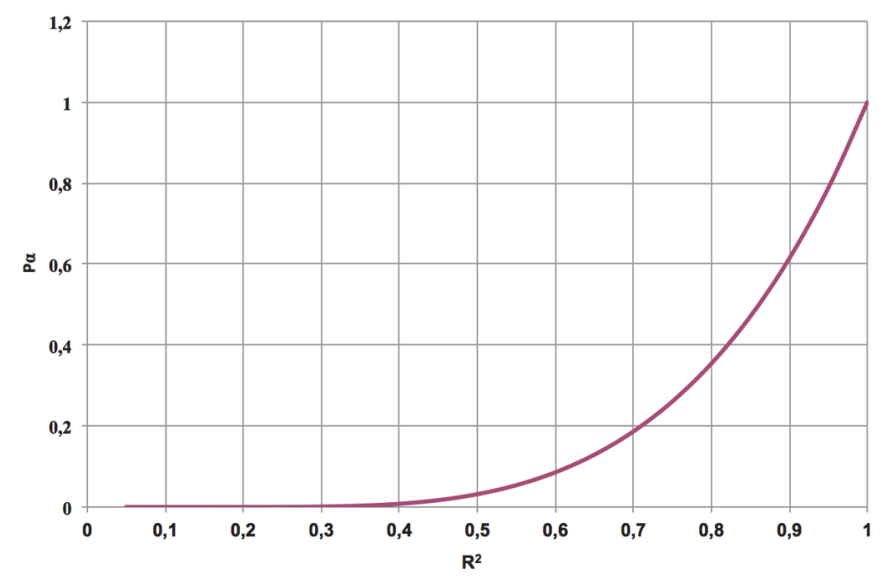

Figure 7. The connection of $R^{2}$ and $\alpha$

It seems well on the Fig. 7 using the exponent, that how the decrease of $\mathrm{R}^{2}$ affects the $\mathrm{P}_{\mathrm{i}}$. Consequently the modified and abated $\mathrm{P}_{\mathrm{i}} \alpha$ has a great role for the final result and can be decided its applicability.

\section{Verification of the model}

To be able to verify the model three types of materials were chosen. These materials have already been defined in the previous chapter. The tests of Stress energy model had been done on same density $\left(25 \mathrm{~kg} / \mathrm{m}^{3}\right)$ foams. To investigate the behaviour of $\mathrm{R}^{2}$ the 6 steps method was performed on each foam type with the following environmental conditions in described Table 2. Table 3 contains the results of $\mathrm{R}^{2}$ after performing all tests and calculations.

Table 2. Combinations of climate conditions

\begin{tabular}{|c|c|c|}
\hline Versions & $\begin{array}{c}\text { Temperature } \\
{\left[{ }^{\mathbf{0}} \mathbf{C}\right]}\end{array}$ & $\begin{array}{c}\text { Relative } \\
\text { Humidity [\%] }\end{array}$ \\
\hline 1 & 23 & 50 \\
\hline 2 & 30 & 65 \\
\hline 3 & 30 & 90 \\
\hline 4 & 40 & 65 \\
\hline 5 & 40 & 90 \\
\hline
\end{tabular}


Table 3. Function of $R^{2}$ values on varied temperature and relative humidity combinations

\begin{tabular}{|c|c|c|c|c|}
\hline Version & $\begin{array}{c}\text { Temperature [ [ }{ }^{\mathbf{0}} \text { ] / } \\
\text { Relative Humidity }\end{array}$ & \multicolumn{3}{|c|}{$\boldsymbol{R}^{\mathbf{2}}$ values in connection with ${ }^{\mathbf{0}}$ C and \% RH } \\
\cline { 3 - 5 } & $\begin{array}{c}\text { [\%] } \\
\text { [\%PS }\end{array}$ & PE & TPS \\
\hline 1 & $23 / 50$ & 0,9536 & 0,9670 & 0,9360 \\
\hline 2 & $30 / 65$ & 0,9737 & 0,9771 & 0,8968 \\
\hline 3 & $30 / 90$ & 0,9345 & 0,9652 & 0,8882 \\
\hline 4 & $40 / 65$ & 0,9370 & 0,9663 & 0,7994 \\
\hline 5 & $40 / 90$ & 0,9397 & 0,9890 & 0,7812 \\
\hline
\end{tabular}

More researchers have also written about that the common plastic cushions haven't showed major change for the temperature and humidity combinations [12] [13]. In case of TPS, which is a humidity sensitive material, the $\mathrm{R}^{2}$ values showed critical decrease. It means that the function fits less and the environmental factors affect significant the cushion characteristic. Based on the previously written, the calculations were accomplished, which is summarized in the Table 4.

Table 4. The cumulated values regarding $\alpha$ and environmental conditions

$23^{\circ} \mathrm{C} / 50 \%$ r.H

\begin{tabular}{|l|c|c|c|c|c|c|c|c|c|c|c|c|c|c|c|c|c|}
\hline & $\mathbf{S}_{\mathbf{i}}$ & $\mathbf{a}_{\mathbf{S}}$ & $\mathbf{Q}_{\mathbf{i}}$ & $\mathbf{a}_{\mathbf{Q}}$ & $\mathbf{E}_{\mathbf{i}}$ & $\mathbf{a}_{\mathbf{E}}$ & $\mathbf{L}_{\mathbf{i}}$ & $\mathbf{a}_{\mathbf{L}}$ & $\mathbf{M}_{\mathbf{i}}$ & $\mathbf{a}_{\mathbf{M}}$ & $\mathbf{P}$ & $\mathbf{a}_{\mathbf{P}}$ & $\mathbf{R}^{\mathbf{2}}$ & $\begin{array}{c}\boldsymbol{\alpha} \\
(\mathbf{m}=\mathbf{1})\end{array}$ & $\mathbf{P}^{\boldsymbol{\alpha}}$ & $\begin{array}{c}\text { Cumulated } \\
\text { values }\end{array}$ & $\begin{array}{c}\Delta \text { values } \\
(\mathbf{\%})\end{array}$ \\
\hline PE & 4 & 35 & 8 & 20 & 5 & 30 & 9 & 30 & 5 & 25 & 10 & 60 & 0,967 & $-0,071$ & 0,849 & 43067,86 & $-0,18$ \\
\hline EPS & 2 & 35 & 7 & 20 & 7 & 30 & 10 & 30 & 7 & 25 & 10 & 60 & 0,9536 & $-0,095$ & 0,803 & 43143,62 & 0,00 \\
\hline TPS & 9 & 35 & 8 & 20 & 1 & 30 & 10 & 30 & 5 & 25 & 10 & 60 & 0,936 & $-0,132$ & 0,737 & 41139,42 & $-4,65$ \\
\hline
\end{tabular}

$40^{\circ} \mathrm{C} / 65 \%$ r.H

\begin{tabular}{|l|c|c|c|c|c|c|c|c|c|c|c|c|c|c|c|c|c|}
\hline & $\mathbf{S}_{\mathbf{i}}$ & $\mathbf{a}_{\mathbf{S}}$ & $\mathbf{Q}_{\mathbf{i}}$ & $\mathbf{a}_{\mathbf{Q}}$ & $\mathbf{E}_{\mathbf{i}}$ & $\mathbf{a}_{\mathbf{E}}$ & $\mathbf{L}_{\mathbf{i}}$ & $\mathbf{a}_{\mathbf{L}}$ & $\mathbf{M}_{\mathbf{i}}$ & $\mathbf{a}_{\mathbf{M}}$ & $\mathbf{P}$ & $\mathbf{a}_{\mathbf{P}}$ & $\mathbf{R}^{\mathbf{2}}$ & $\begin{array}{c}\boldsymbol{\alpha} \\
(\mathbf{m}=\mathbf{1})\end{array}$ & $\mathbf{P}^{\boldsymbol{\alpha}}$ & $\begin{array}{c}\text { cumulated } \\
\text { value }\end{array}$ & $\begin{array}{c}\Delta \text { values } \\
(\mathbf{\%})\end{array}$ \\
\hline PE & 4 & 35 & 8 & 20 & 5 & 30 & 9 & 30 & 5 & 25 & 10 & 60 & 0,9652 & $-0,022$ & 0,95 & 48182,09 & 0,00 \\
\hline EPS & 2 & 35 & 7 & 20 & 7 & 30 & 10 & 30 & 7 & 25 & 10 & 60 & 0,9345 & $-0,136$ & 0,732 & 39299,17 & $-18,44$ \\
\hline TPS & 9 & 35 & 8 & 20 & 1 & 30 & 10 & 30 & 5 & 25 & 10 & 60 & 0,8882 & $-0,238$ & 0,579 & 32282,09 & $-33,00$ \\
\hline
\end{tabular}

$40{ }^{\circ} \mathrm{C} / 90 \%$ r.H

\begin{tabular}{|l|c|c|c|c|c|c|c|c|c|c|c|c|c|c|c|c|c|}
\hline & $\mathbf{S}_{\mathbf{i}}$ & $\mathbf{a}_{\mathbf{S}}$ & $\mathbf{Q}_{\mathbf{i}}$ & $\mathbf{a}_{\mathbf{Q}}$ & $\mathbf{E}_{\mathbf{i}}$ & $\mathbf{a}_{\mathbf{E}}$ & $\mathbf{L}_{\mathbf{i}}$ & $\mathbf{a}_{\mathbf{L}}$ & $\mathbf{M}_{\mathbf{i}}$ & $\mathbf{a}_{\mathbf{M}}$ & $\mathbf{P}$ & $\mathbf{a}_{\mathbf{P}}$ & $\mathbf{R}^{2}$ & $\begin{array}{c}\boldsymbol{\alpha} \\
(\mathbf{m}=\mathbf{1})\end{array}$ & $\mathbf{P}^{\boldsymbol{\alpha}}$ & $\begin{array}{c}\text { cumulated } \\
\text { value }\end{array}$ & $\begin{array}{c}\Delta \text { values } \\
(\mathbf{\%})\end{array}$ \\
\hline PE & 4 & 35 & 8 & 20 & 5 & 30 & 9 & 30 & 5 & 25 & 10 & 60 & 0,989 & $-0,022$ & 0,95 & 48182,09 & 0,00 \\
\hline EPS & 2 & 35 & 7 & 20 & 7 & 30 & 10 & 30 & 7 & 25 & 10 & 60 & 0,9397 & $-0,124$ & 0,751 & 40318,55 & $-16,32$ \\
\hline TPS & 9 & 35 & 8 & 20 & 1 & 30 & 10 & 30 & 5 & 25 & 10 & 60 & 0,7812 & $-0,499$ & 0,317 & 17691,00 & $-63,28$ \\
\hline
\end{tabular}

It is clearly seen from the last column of the Table 4 that the difference between humidity sensitive material and the non-sensitive materials is getting more and more. From this verification process, the following consequences can be drawn:

- The environmentally friendly TPS foam can be a good alternative for replacing the common plastic foams, if the logistic flow happened on controlled normal climate (cc: $23^{\circ} \mathrm{C} / 50 \% \mathrm{RH}$ ) 
- If the climate parameters show high relative humidity during the transportation, the sensitive materials are even less suitable, namely when the mechanical characteristic of a cushion gets high priority in the PPS.

- When the final aggregated value of a sensitive material is very low comparing the others, the required packaging protection should be solved with the modification of cushioning characteristic (thickness, etc.) or other packaging technology solutions, like moisture resist outer packaging, etc. Naturally, these modifications degrade the other category values like Logistics $\left(\mathrm{L}_{\mathrm{i}}\right)$, Supply $\left(\mathrm{S}_{\mathrm{i}}\right)$, etc.

\section{Conclusion}

For that cases, when the environmental conditions (temperature / humidity combination) show extremely varies or the possible applicable material is humidity sensitive, like paper, paperboard, TPS, etc., or the cushioning characteristic of the packaging system is important, our extended and modified model can be applied. This extended function takes into account the cushioning behaviour of material as well, which is based on cushion curve tests and Stress-Energy calculations on different environmental conditions.

The verifications of both models showed that these functions can be applicable in practice and can give helping hand for the packaging engineer, to accelerate the packaging development and designing processes.

\section{References}

[1] Dowlatshahi S: A modeling approach to logistics in concurrent engineering. European Journal of Operational Research, Vol. 115, No. 1, 59-76., 1999. DOI: 10.1080/10170660609508994

[2] Bucci DZ; Forcellini FA: Sustainable packaging design model, Complex Systems Concurrent Engineering. Springer London, p. 363-370., 2007.

[3] Barmklev C, Bjärnemo R, Jönson J, Johnsson M: Towards an Integrated Design of Product and Packaging. International Conference On Engineering Design, ICED 05, August 15-18, Melborne, 2005.

[4] Pánczél Z: The significance of logistic package system design. Acta Technica Jaurinensis, Vol. 1, No. 2, pp. 247-257, 2008

[5] Rouillard V, Sek MA, Perry T: Analysis and simulation of road profiles. Journal of transportation engineering, Vol. 122, No. 3, pp. 241-245, 1996.

DOI: 10.1061/(ASCE)0733-947X(1996)122:3(241)

[6] Singh SP, Chonhenchob V, Burgess G: Comparison of Various Loose Fill Cushioning Materials Based on Protective and Environmental Performance, Packaging Technology and Science, Vol. 7, pp. 229-241, 1994.

DOI: $10.1002 /$ pts. 2770070504

[7] Sek M, Kirkpatrick J: Characteristics of corrugated fibreboard as a cushioning material in protective packaging, 10th IAPRI World Conference on Packaging, pp. 257-266, Melbourne, 1997. 
[8] Sek MA, Minett M, Rouillard V, Bruscella B: A new method for the determination of cushion curves. Packaging Technology and Science, Vol. 13, No. 6, pp. 249-255, 2000.

DOI: $10.1002 /$ pts. 517

[9] Mojzes Á, Földesi P, Böröcz P: Define cushion curves for environmental friendly packaging foam. International Journal of Engineering Vol. 10, No. 1, pp. 113-118, Hunedoara, Romania, 2012.

[10] Mojzes Á, Böröcz P: Predicting Cushion Characteristic on New Type of Environmental Friendly Foam. Acta Technica Jaurinensis Vol. 3, No. 3, pp. 395404, 2010.

[11] Burgess G: Generation of Cushion Curves from One Shock Pulse. Packaging Technology and Science, Vol. 7, No. 4, pp. 169-174, 1994.

DOI: $10.1002 /$ pts. 2770070403

[12] Mills NJ, Gilcrist A: Creep and recovery of polyolefin foams - deformation mechanisms. Journal of cellular plastics, Vol. 33, No. 3, pp. 264-292, 1997. 